\title{
Psychological and Communication Characteristics of Opinion Leaders: With Special Reference to Farm Women in Uttarakhand
}

\author{
Neelam Basera*, Arpit Huria and Neelam Bhardwaj \\ Department of Agricultural Communication, College of Agriculture, G. B. Pant University of \\ Agriculture and Technology, Pantnagar, Uttarakhand, India \\ *Corresponding author
}

\section{A B S T R A C T}

\section{Keywords}

Farm women, Communication characteristics, Hill women, Opinion leaders, Psychological characteristics

\section{Article Info}

Accepted:

04 August 2020

Available Online:

10 September 2020
The study was carried out in one of the hill state of India, Uttarakhand. The research was confined to two hill villages selected at random from Kumaon and Garhwal division respectively. The present paper is centred on understanding the psychological and communication characteristics of opinion leaders identified among the farm women. Out of 298 respondents selected as sample for the study, twenty four respondents were revealed to influence the actions and decisions of fellow farm women. Not only, had they exhibited different degree of influence, but showed relative difference in characteristics. The findings revealed that majority of the opinion leaders had medium level of innovativeness, achievement motivation, economic motivation, decision making ability, scientific orientation, risk preferences, cosmopoliteness and social participation. However, media ownership was found to be low among maximum of the opinion leaders due to the non-availability of media resources. Still, few among them showed high level of psychological and communication characteristics complementing their role as opinion leaders.

\section{Introduction}

The role and status of women in hills is different from those in plain regions. Owing to migration, more and more women in hills are primarily responsible for managing both farm and home. Hill farming has its own challenges - undulating topography, fragmented and scattered land holdings, poor and shallow soils prone to erosion, leading to soil degradation and more. Women are thus, the major actors involved in running the household economy. Due to limited access and availability of information and communication sources, women rely much more on other fellow women on day to day basis when compared to any external information source. The reliance of farm women on these few others may be accounted to the distinguishable characteristics exhibited in terms of influence. These few individuals are capable of influencing the actions and decisions of others and so are often known as opinion leaders. Studies have been conducted across disciplines to study the phenomenon of opinion leadership. However, an insight on 
the characteristics of opinion leaders with particular reference to the specific situations of women in hills in their peculiar geographical location provides a broader perspective on opinion leadership. The present paper is an attempt to discuss the psychological and communication characteristics of opinion leaders among the farm women in the selected two hill villages.

\section{Materials and Methods}

The study was carried out in Uttarakhand. For the selection of respondents, multi stage sampling procedure was adopted. Out of total thirteen districts of Uttarakhand, district Bageshwar from Kumaon division and district TehriGarhwal from Garhwal division were selected using simple random sampling without replacement. Village Badiyakot from Kapkot block of Bageshwar and village SabliTalli from Chamba block of district TehriGarhwal were selected using simple random sampling without replacement. A total of 298 farm women i.e. 177 respondents from village Badiyakot and 121 respondents from village SabliTalli were purposively selected as respondents based on following criteria for selection:

Farm women who were extensively involved in agriculture and allied activities

Farm women who were over the age of eighteen years and above

\section{Identification of Opinion leaders}

Out of 298 respondents, twenty four opinion leaders were identified using their high In degree centrality scores. The In degree centrality scores were calculated for each respondent using UCINET software. The study followed descriptive research design. The quantitative information was collected through semi-structured interview schedule pre-tested and modified accordingly based on pilot study. The data collected were coded, tabulated, analysed and interpreted with the help of SPSS software.

\section{Results and Discussion}

\section{Psychological Characteristics of Opinion Leaders}

The following psychological characteristics of opinion leaders were studied:

\section{Innovativeness}

Innovativeness was operationalized as the degree to which a respondent was relatively earlier in adopting new ideas in relation to agriculture and allied activities. Jaussi and Dionne (2003) scale was taken into consideration. The data in Table 1 indicated that majority of the opinion leaders $(70.84 \%)$ had medium level of innovativeness. About 16.67 per cent of opinion leaders belonged to high level of innovativeness followed by only 12.50 per cent of opinion leaders who belonged to low level of innovativeness respectively.

\section{Achievement motivation}

Achievement motivation was operationalized as the personality orientation of respondents impelling her to strive something excellent. The scale developed by Yadav (2004) was used. The findings showed that about three-fourth of the opinion leaders $(75.00 \%)$ had medium level of achievement motivation followed by 16.67 per cent who had high level of achievement motivation respectively. Only 8.33 per cent of opinion leaders belonged to low level of achievement motivation. Interestingly, individuals that were identified as having the most knowledge about a particular issue tended to have similar characteristics: they were more likely to be motivated. 
Table.1 Distribution of opinion leaders on the basis of psychological characteristics

\begin{tabular}{|c|c|c|c|c|}
\hline Characteristics & Frequency & Percentage $(\%)$ & Mean & Standard deviation \\
\hline \multicolumn{5}{|l|}{ Innovativeness } \\
\hline Low (Less than 19.56) & 3 & 12.50 & \multirow{3}{*}{22.79} & \multirow{3}{*}{3.230} \\
\hline Medium (19.56 to 26.02) & 17 & 70.84 & & \\
\hline High (More than 26.02) & 4 & 16.67 & & \\
\hline \multicolumn{5}{|l|}{ Achievement motivation } \\
\hline Low ( Less than 18.90) & 2 & 8.33 & \multirow{3}{*}{23.38} & \multirow{3}{*}{4.480} \\
\hline Medium (18.90 to 27.86$)$ & 18 & 75.00 & & \\
\hline High (More than 27.86) & 4 & 16.67 & & \\
\hline \multicolumn{5}{|l|}{ Scientific orientation } \\
\hline Low ( Less than 16.61) & 3 & 12.50 & \multirow{3}{*}{20.62} & \multirow{3}{*}{4.009} \\
\hline Medium (16.61 to 24.63$)$ & 17 & 70.84 & & \\
\hline High (More than 24.63) & 4 & 16.67 & & \\
\hline \multicolumn{5}{|l|}{ Risk preference } \\
\hline Low (Less than 16.17) & 4 & 16.67 & \multirow{3}{*}{19.21} & \multirow{3}{*}{3.036} \\
\hline Medium (16.17 to 22.25$)$ & 17 & 70.84 & & \\
\hline High (More than 22.25) & 3 & 12.50 & & \\
\hline \multicolumn{5}{|l|}{ Decision making ability } \\
\hline Low (Less than13.59) & 4 & 16.67 & \multirow{3}{*}{15.46} & \multirow{3}{*}{1.865} \\
\hline Medium (13.59 to 17.33$)$ & 17 & 70.84 & & \\
\hline High (More than 17.33) & 3 & 12.50 & & \\
\hline \multicolumn{5}{|l|}{ Economic motivation } \\
\hline Low (Less than 18.84) & 1 & 4.17 & \multirow{3}{*}{21.71} & \multirow{3}{*}{2.866} \\
\hline Medium (18.84 to 24.58$)$ & 20 & 83.33 & & \\
\hline High (More than 24.58) & 3 & 12.50 & & \\
\hline
\end{tabular}

**Total Number of Opinion Leaders: 24

Table.2 Distribution of opinion leaders according to communication characteristics

\begin{tabular}{|c|c|c|c|c|}
\hline Characteristics & Frequency & Percentage (\%) & Mean & Standard deviation \\
\hline \multicolumn{5}{|l|}{ Media ownership } \\
\hline Low (Less than 2.03) & 10 & 41.67 & \multirow{3}{*}{2.88} & \multirow{3}{*}{0.850} \\
\hline Medium (2.03 to 3.73$)$ & 7 & 29.17 & & \\
\hline High (More than 3.73) & 7 & 29.17 & & \\
\hline \multicolumn{5}{|l|}{ Cosmopoliteness } \\
\hline Low (Less than 4.19 & 8 & 33.33 & \multirow{3}{*}{5.54} & \multirow{3}{*}{1.351} \\
\hline Medium ( 4.19 to 6.89 ) & 10 & 41.67 & & \\
\hline High (More than 6.89) & 6 & 25.00 & & \\
\hline \multicolumn{5}{|l|}{ Social participation } \\
\hline Low (Less than 10.23) & 6 & 25.00 & \multirow{3}{*}{12.46} & \multirow{3}{*}{2.226} \\
\hline Medium (10.23 to 14.69) & 14 & 58.33 & & \\
\hline High (More than 14.69) & 4 & 16.67 & & \\
\hline
\end{tabular}

**Total Number of Opinion Leaders: 24 


\section{Scientific orientation}

Scientific orientation was measured as the degree to which a farmer was oriented to the use of scientific methods in decision making and farming operations. It was measured using the scale developed by Supe (2007). The data in Table 1 exhibited that majority of the opinion leaders $(70.84 \%)$ belonged to medium category of scientific orientation. While the remaining 16.67 per cent and 12.50 per cent of opinion leaders had high and low level of scientific orientation respectively. This is possibly due to the fact that the local leaders were usually innovative and they generally had more risk oriented dynamic, educated and knowledgeable.

\section{Risk preference}

Risk preference was operationalized as the degree to which a respondent was oriented towards risk and uncertainty for using new technology related to agriculture and allied activities and has the courage to face the problems in farming. The variable was measured with the help of scale developed by Supe (2007). The data in Table 1 illustrated that majority $(70.84 \%)$ of the opinion leaders had medium level of risk preference. About 16.67 per cent and 12.50 per cent of opinion leaders had high and low preference to risks respectively.

\section{Decision making ability}

Decision making ability was operationalized as the degree to which an individual justifies her selection of most efficient means from among the available alternatives on the basis of scientific criteria for achieving maximum economic profits. To measure this aspect scale developed by Nandapurkar (1981) was used. The data in Table 1 revealed that majority $(70.84 \%)$ of the opinion leaders had medium level of decision making ability.
About 16.67 per cent and 12.50 per cent of opinion leaders had high and low decision making ability respectively.

\section{Economic motivation}

Economic motivation was operationalized as the occupational success defined in terms of profit maximization and the relative value placed by a farm woman on economic ends. The variable was measured with the help of scale developed by Supe (2007). The data regarding the distribution of opinion leaders according to their economic motivation presented in Table 1 depicted that majority of the opinion leaders $(83.33 \%)$ had medium level of economic motivation followed by 12.50 per cent who had high level of economic motivation respectively. Only 4.17 per cent of opinion leaders belonged to low level of economic motivation.

\section{Communication characteristics of opinion leaders}

The following communication characteristics of opinion leaders were studied:

\section{Media ownership}

Media ownership was operationalized as the number of media possessed by the respondent's family. It included the possession of radio, television, mobile phone, newspaper, magazines, internet, etc. by the respondents. The data in Table 2 indicated that maximum percentage of the opinion leaders (41.67\%) had low media ownership (less than two). Equal percentages of opinion leaders $(29.17 \%)$ exhibited medium and high media ownership respectively. Lack of proper and continuous electricity and low educational status might be the probable reasons for low media ownership among the opinion leaders identified in the sampled villages. It was also observed that among all 
the media, television and mobile phones were mostly owned by the farm women in the respective villages under study.

\section{Cosmopoliteness}

Cosmopoliteness referred to the degree to which the respondent was oriented towards her immediate source outside social system. This variable was measured using the procedure suggested by Gangappa (1975) and followed by Hardikar (1998). The distribution of opinion leaders on the basis of their cosmopoliteness is presented in Table 2. The data revealed that most of the opinion leaders $(41.67 \%)$ had medium level of cosmopoliteness followed by one third of opinion leaders (33.33\%) who had low cosmopoliteness. The remaining 25 per cent of opinion leaders had high cosmopoliteness respectively.

\section{Social participation}

Social participation was defined as voluntary sharing or degree of involvement of respondents in various formal and informal social organizations simply as a member or as an office bearer. It was calculated on the basis of nature of participation and number of organizations in which respondents has participated. This variable was measured by using the scale developed by Nirban (2004). The composition of opinion leaders on the basis of their social participation is presented in Table 2. It showed that maximum percentage of opinion leaders $(58.33 \%)$ had medium social participation followed by 25.00 per cent of opinion leaders who had low social participation. The remaining 16.67 per cent of opinion leaders had high social participation respectively. It was observed that opinion leaders in the study area showed active participation in social organizations such as NGOs, KVK and so on.
In conclusion the opinion leaders identified among the farm women were mostly followed by others in the sampled villages. Opinion leaders showed medium level of innovativeness, achievement motivation, economic motivation, decision making ability, scientific orientation, risk preferences, cosmopoliteness and social participation. Still, few among them exhibited high level of psychological and communication characteristics complementing their role as opinion leaders. In contrast, media ownership was found to be low among maximum of the opinion leaders which was due to the nonavailability of media resources. It was noticed that the identified opinion leaders were mostly the ones who were highly motivated and aware of their surroundings. They showed higher level of interest and understanding towards new scientific methods and technologies when compared to others. This further adds to the need to explore more on opinion leadership studies focused on indepth investigation with wider generalisations and applications.

\section{References}

Gangappa, G. N. 1975. A study of adoption behavior consultancy pattern and information source credibility of small farmers in Mysore district of Karnataka state. Thesis, M.Sc. University of Agricultural Sciences, Bengaluru.

Hardikar, D.P. 1998. Perception of Development programme and benefits derived by women beneficiaries of Ratnagiri district. Thesis, Ph.D. University of Agricultural Sciences, Dharwad.

Jaussi, K., and Dionne, S. 2003. Leading for creativity: The role of unconventional leader behavior. The Leadership Quarterly, 14(4-5), 475-498.

Nanadapurkar, G. G. 1981. Small farmers: A study on their entrepreneurial behaviour, 
Metropoliton book cooperative Pvt. Ltd., New Delhi.

Nirban, A.J. 2004.Analysis of the agricultural produce market committees in Konkan and Western Maharashtra with reference to their potential role in agricultural marketing extension. Thesis, Ph.D.
Mahatma Phule Krishi Vidyapeeth. Rahuri, Maharashtra, India.

Supe, S.V. 2007.Measurement techniques in social sciences. Agrotech Publishing Academy, Udaipur.

\section{How to cite this article:}

Neelam Basera, Arpit Huria and Neelam Bhardwaj. 2020. Psychological and Communication Characteristics of Opinion Leaders: With Special Reference to Farm Women in Uttarakhand. Int.J.Curr.Microbiol.App.Sci. 9(09): 258-263. doi: https://doi.org/10.20546/ijcmas.2020.909.032 